\title{
BIOCHEMICAL MARKERS OF ENDOTHELIAL DYSFUNCTION, THEIR CHANGES UNDER THE INFLUENCE OF TREATMENT WITH VARIOUS BETA-ADRENOBLOCKERS IN YOUNG MEN WITH MYOCARDIAL INFARCTION
}

DOI: 10.36740/WLek202103211

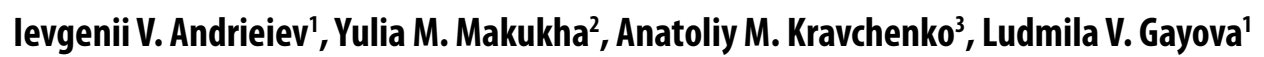 \\ 'BOGOMOLETS NATIONAL MEDICAL UNIVERSITY, KYIV, UKRAINE \\ ${ }^{2}$ ALEXANDER CLINICAL HOSPITAL IN KYIV, UKRAINE \\ 3STATE INSTITUTION OF SCIENCE «RESEARCH AND PRACTICAL CENTER OF PREVENTIVE AND CLINICAL MEDICINE» STATE ADMINISTRATIVE \\ DEPARTMENT, KYIV, UKRAINE
}

\begin{abstract}
The aim: Is to determine the levels of markers of endothelial dysfunction in young men with myocardial infarction and their changes during the treatment with beta-blockers with different pharmacological properties.

Materials and methods: 112 male patients of Caucasian race of the Ukrainian population under the age of 50 with MI. Group I received Nebivolol, group II - bisoprolol. Results: During the 6-month follow-up, positive dynamics of NOS-2 and ET-1 was observed. The level of NOS-2 in groups I - II was 4272.3 $\pm 162.7,4629.7 \pm 161.2 \mathrm{pg} / \mathrm{mL}$, respectively $(p<0.05)$. The dynamics of ET-1 showed significant decrease of its level in all groups

Conclusions: Significant changes in markers of endothelial dysfunction, namely NOS3/eNOS, NOS2/iNOS and ET-1, are observed in young male patients of the Ukrainian population with MI. During 6 months of treatment, positive changes were observed in the form of an increase in NOS-3 levels and a significant decrease in ET- 1 and NOS-2 levels. The inclusion of Nebivolol in the basic therapy for this group of patients is associated with an additional positive effect on the normalization of levels N0 synthase and the reduction of ET-1.
\end{abstract}

KEY WORDS: myocardial infarction, nebivolol, N0 synthase, endothelin-1

\section{INTRODUCTION}

Despite advances in the treatment of cardiovascular diseases, the prevalence and availability of endovascular interventions, the issue of treatment of myocardial infarction (MI) in Ukraine remains relevant. Diseases of the circulatory system are the most common pathology in the structure of the general morbidity of the population of Ukraine and take a leading place in the structure of primary disability and total mortality ( $23.7 \%$ and $65 \%$, respectively). Coronary heart disease ranks first in the structure of mortality in diseases of the circulatory system, the proportion of which was $69 \%$. 16 to $19.5 \%$ of patients die of MI and its complications at working age. A separate part is $\mathrm{MI}$ in men of working age in terms of disability.

Regulation of myocardial function by NO synthase (NOS) is important for maintaining myocardial homeostasis, relaxation (diastolic function) and protection against arrhythmia. However, lesions of the cardiovascular system lead to NOS dysfunction with the synthesis of superoxide instead of NO. Another important marker is endothelin-1 (ET-1). ET-1 is a potent coronary vasoconstrictor peptide. ET-1 plasma levels increase after MI and reperfusion in humans. This apparently contributes to the narrowing of the coronary vessels, which at the time underlies myocardial ischemia and ventricular dysfunction. Studies have shown that elevated levels of ET-1 are a poor prognostic marker after reperfusion [1].

To date, there are a large number of studies that indicate significant changes in endothelial function in MI. Therefore, the search for drugs for its correction is an urgent task. The advance technique is a racemic mixture of $\mathrm{d}$ - and l-nebivolol, a selective third-generation b1-adrenoceptor blocker with $\mathrm{NO}$-mediated vasodilator and antioxidant properties. It reduces superoxide in endothelial cells to increase the bioavailability of $\mathrm{NO}$ [2] and can inhibit NADPH oxidase activity. This leads to a net increase in NO production with increasing NOS3 activity. Such activity is observed in both the endothelium and the heart, although activation of NOS3 was not observed in end-stage heart failure in humans. The effect of Nebivolol on the heart is associated with stimulation of $\mathrm{b} 3-\mathrm{AR}$, which enhances NO synthase and promotes angiogenesis, suggesting its possible use in ischemic injury and reperfusion [3]. To date, there have been only a few controlled clinical trials. The SENIORS trial (Study of the Effects of Nebivolol in the Elderly With Heart Failure) demonstrated that Nebivolol 
Table I. Clinical characteristics of the examined patients

\begin{tabular}{|c|c|c|c|c|}
\hline & & $\begin{array}{l}\text { Patients } \\
(n=112)\end{array}$ & $\begin{array}{c}\text { CG } \\
(n=35)\end{array}$ & $\mathbf{p}$ \\
\hline 1. & Age, years $M \pm m$ & $41,9 \pm 2,8$ & $41,4 \pm 2,9$ & $>0.05$ \\
\hline 2. & Smoking, abs. (\%) & $73(65.2 \%)$ & $17(48.6 \%)$ & $>0.05$ \\
\hline 3. & Hypertension, abs. (\%) & $9(8,0 \%)$ & 0 & $<0.05$ \\
\hline 4. & Family history, abs. (\%) & $32(28.6 \%)$ & $6(17.1 \%)$ & $>0.05$ \\
\hline
\end{tabular}

Table II. Clinical characteristics of patients of groups I, II and III who took BAB

\begin{tabular}{|c|c|c|c|c|c|c|c|}
\hline & & $\begin{array}{l}\text { I group } \\
(n=37)\end{array}$ & $\begin{array}{l}\text { II group } \\
(n=44)\end{array}$ & $\begin{array}{l}\text { III group } \\
(n=31)\end{array}$ & p1 & p2 & p3 \\
\hline 1. & Age, years $M \pm m$ & $42,1 \pm 2,9$ & $41,7 \pm 3,0$ & $42,2 \pm 2,7$ & $>0.05$ & $>0.05$ & $>0.05$ \\
\hline 2. & Smoking, abs. (\%) & $23(62.2 \%)$ & $28(63.6 \%)$ & $22(71,0 \%)$ & $>0.05$ & $>0.05$ & $>0.05$ \\
\hline 3. & Hypertension, abs. (\%) & $3(8,1 \%)$ & $2(4,6 \%)$ & $4(12,9 \%)$ & $>0.05$ & $>0.05$ & $>0.05$ \\
\hline 4. & Family history, abs. (\%) & $10(27.0 \%)$ & $12(27.3 \%)$ & $10(32,3 \%)$ & $>0.05$ & $>0.05$ & $>0.05$ \\
\hline 5. & $\mathrm{BMl}>30 \mathrm{~kg} / \mathrm{m}^{2}$ abs. (\%) & $4(10.8 \%)$ & $3(6.8 \%)$ & $5(16,1 \%)$ & $>0.05$ & $>0.05$ & $>0.05$ \\
\hline
\end{tabular}

Note: $P 1$ value for differences between the indicators of groups I and II

$P 2$ value for differences between the indicators of groups I and III

P3 value for differences between the indicators of groups II and III

Table III. Characteristics of coronary artery disease and endovascular interventions in patients

\begin{tabular}{|c|c|c|c|c|c|c|c|}
\hline & & $\begin{array}{l}\text { Group I } \\
(n=37)\end{array}$ & $\begin{array}{c}\text { Group II } \\
(n=44)\end{array}$ & $\begin{array}{c}\text { Group III } \\
(n=31)\end{array}$ & p1 & p2 & p3 \\
\hline 1. & Single-vessel disease, abs. (\%) & $7(18.9 \%)$ & $9(20.5 \%)$ & $9(29,0 \%)$ & $>0.05$ & $>0.05$ & $>0.05$ \\
\hline 2. & Two-vessel disease, abs. (\%) & $12(32,4 \%)$ & $16(36,4 \%)$ & $9(29,0 \%)$ & $>0.05$ & $>0.05$ & $>0.05$ \\
\hline 3. & Three-vessel disease, abs. (\%) & $18(48.7 \%)$ & $19(43.2 \%)$ & $13(42,0)$ & $>0.05$ & $>0.05$ & $>0.05$ \\
\hline 4. & 1 stent, abs. (\%) & $34(91,9 \%)$ & $40(90,9 \%)$ & $26(83,9 \%)$ & $>0.05$ & $>0.05$ & $>0.05$ \\
\hline 5. & 2 stents, abs. (\%) & $1(2,7 \%)$ & $3(6,8 \%)$ & $3(9,7 \%)$ & $>0.05$ & $>0.05$ & $>0.05$ \\
\hline 6. & 3 or more stents, abs. (\%) & $2(5,4 \%)$ & $1(2,3 \%)$ & $2(6,4 \%)$ & $>0.05$ & $>0.05$ & $>0.05$ \\
\hline
\end{tabular}

Note: P1 value for differences between the indicators of groups I and II

$P 2$ value for differences between the indicators of groups I and III

P3 value for differences between the indicators of groups II and III

caused a moderate reduction in all causes of death or hospitalization due to cardiovascular disease [4].

However, the patients of young age were not taken into account separately or performed in experimental animal models. There are no studies on the effect of drugs with the existing mechanism of NO activity on the biochemical parameters of endothelial dysfunction in MI in men of working age.

\section{THE AIM}

Aim of the study is to determine the levels of markers of endothelial dysfunction in young men with myocardial infarction and their changes during the treatment with beta-blockers with different pharmacological properties.

\section{MATERIALS AND METHODS}

112 male patients of Caucasian race of the Ukrainian population under the age of 50 (mean $43.21 \pm 2.8$ years) who have had MI and underwent rehabilitation and treatment in the rehabilitation department of the Alexander Clinical Hospital in Kyiv in 2015-2018 were examined. The diagnosis of MI was established on ESC criteria (2012).

The study did not include patients with concomitant diabetes mellitus, valvular heart disease, familial hyperlipidemia and NYHA class III-IV heart failure. Patients with grade II/III arterial hypertension were also excluded. The patients with the presence of grade I hypertension in the anamnesis were admitted (see Table I). To obtain normative indicators, 35 men of the appropriate age without diseases of the cardiovascular system were examined according to clinical and anamnestic data along with the results of instrumental examinations - control group (CG). All the patients, including CG, signed an informed consent before participating to the study in accordance with the requirements of the GCP. The study has the approval of the local ethics commission (№ 3 from 01.02.18). 
Table IV. Drug therapy of patients of the studied groups

\begin{tabular}{|c|c|c|c|c|c|c|c|}
\hline & & $\begin{array}{c}\text { Group I } \\
(n=37)\end{array}$ & $\begin{array}{c}\text { Group II } \\
(n=44)\end{array}$ & $\begin{array}{c}\text { Group III } \\
(\mathbf{n}=\mathbf{3 1})\end{array}$ & p1 & p2 & p3 \\
\hline 1. & Rosuvastatin, abs. (\%) & $21(56,8 \%)$ & $27(61,4 \%)$ & $23(74,2 \%)$ & $>0.05$ & $>0.05$ & $>0.05$ \\
\hline 2. & Atorvastatin, abs. (\%) & $16(43,2 \%)$ & $17(38,6 \%)$ & $8(25,8 \%)$ & $>0.05$ & $>0.05$ & $>0.05$ \\
\hline 3. & Acetylsalicylic acid, abs. (\%) & $37(100 \%)$ & $37(100 \%)$ & $37(100 \%)$ & $>0.05$ & $>0.05$ & $>0.05$ \\
\hline 4. & ACE inhibitor, abs. (\%) & $32(86,5 \%)$ & $40(90,9 \%)$ & $29(93,6 \%)$ & $>0.05$ & $>0.05$ & $>0.05$ \\
\hline 6. & Clopidogrel, abs. (\%) & $19(51,4 \%)$ & $20(45,5 \%)$ & $17(54,8 \%)$ & $>0.05$ & $>0.05$ & $>0.05$ \\
\hline 7. & Ticagrelor, abs. (\%) & $18(48,6 \%)$ & $24(54,5 \%)$ & $14(45,2 \%)$ & $>0.05$ & $>0.05$ & $>0.05$ \\
\hline
\end{tabular}

Note: $P 1$ value for differences between the indicators of groups I and II

$P 2$ value for differences between the indicators of groups I and III

P3 value for differences between the indicators of groups II and III

Table V. Changes in endoletial dysfunction in the study groups of patients, $\mathrm{pg} / \mathrm{mL}(\mathrm{M} \pm \sigma)$

\begin{tabular}{|c|c|c|c|c|c|c|c|c|c|c|c|}
\hline \multirow{2}{*}{ № } & & \multicolumn{2}{|c|}{ Group I } & \multirow{2}{*}{$\mathbf{p}$} & \multicolumn{2}{|c|}{ Group II } & \multirow[t]{2}{*}{$n$} & \multicolumn{2}{|c|}{ Group III } & \multirow{2}{*}{$\mathbf{p}$} & \multirow{2}{*}{ CG } \\
\hline & & baseline & 6 months & & baseline & 6 months & & baseline & 6 months & & \\
\hline 1 & $\mathrm{NOS}-2$ & $4851,1 \pm 166,5^{*}$ & $4272,3 \pm 162,7^{* \#}$ & $<0.05$ & $4837,7 \pm 159,3^{*}$ & $4629,7 \pm 161,2^{8^{*}}$ & $<0.05$ & $4853,4 \pm 165,4^{*}$ & $4634,2 \pm 163,5^{8^{*}}$ & $<0.05$ & $4095,1 \pm 161,9$ \\
\hline 2 & NOS -3 & $3088,1 \pm 153,1^{*}$ & $3428,9 \pm 154,3^{*} \#$ & $<0.05$ & $3093,4 \pm 157,4^{*}$ & $3212,4 \pm 149,7^{8^{*}}$ & $<0.05$ & $3086,3 \pm 152,3^{*}$ & $3248,7 \pm 155,1^{8^{*}}$ & $<0.05$ & $3545,0 \pm 159,8$ \\
\hline 3 & ET -1 & $62,1 \pm 5,4^{*}$ & $54,7 \pm 6,1^{*} \#$ & $<0.05$ & $63,1 \pm 3,9^{*}$ & $59,6 \pm 3,3^{8^{*}}$ & $<0.05$ & $62,3 \pm 4,8^{*}$ & $60,2 \pm 4,2^{2^{*}}$ & $<0.05$ & $50,6 \pm 5,7$ \\
\hline
\end{tabular}

Note: $p$ - the accuracy of the difference between the indicators at the beginning and after 6 months of treatment

* $-p<0.05$ in comparison with CG

$\&-p<0.05$ in comparison with the corresponding indicators of group I

$\#-p<0.05$ in comparison with the corresponding indicators of group II

Upon admission, all examined patients underwent urgent coronary angiocardiography (CAG) and primary percutaneous angioplasty with stenting according to the time terms according to the recommendations of ESC (2012).

All patients and CG underwent a general clinical examination, complete blood count, plasma glucose, biochemical parameters according to the recommendations of ESC (2012) and the local protocol of management of patients at the Alexander Clinical Hospital in Kyiv. All patients regularly underwent ECG at rest using the hardware and software complex Mortara R-scribe (Mortara Instrument, Inc., USA). The parameters of heart rate, intervals $R-R$, QRS, QT, PQ were measured, the dynamics of focal changes was estimated.

Determination of NOS-2, NOS-3 and ET-1 levels was performed on the basis of the Research Institute of Experimental Therapy of the Bogomolets National Medical University by the enzyme-linked immunosorbent assay using the ELABSCIENCE test system (USA) on a photometric system with a digital control system Rayto RT-2100C (PRC). All examinations were performed on days 10-14 of MI and after 6 months of treatment.

Two groups of patients were singled out to determine the effect of beta-blockers (BAB) on endothelial function. Group I (37 patients) received Nebivolol («Nebilet» by Berlin-Chemie AG), group II (44 patients) received bisoprolol («Concor» by Merck Ltd). Both groups were comparable according to clinical and anamnestic data (see Table II).

31 patients (group III) had contraindications to the administration of $\mathrm{BAB}$, mainly due to initial bradycar- dia or severe bradycardia to the minimum dose of $\mathrm{BAB}$ (26 patients). 5 patients were not prescribed for other reasons.

Microsoft Excel (Microsoft Corporation, USA), IBM SPSS Statistics 22 for Windows (IBM SPSS Statistics, USA) were used for data management and analysis. F-test was used to compare categorical variables between the study groups. Nonparametric statistics were used to compare continuous variables: the Wilcoxon test for related sets and the Mann - Whitney U-test for unrelated sets.

\section{RESULTS}

No fatal outcomes were observed in the study and control groups during the entire follow-up period. When prescribing $\mathrm{BAB}$ no adverse effects (side effects) were observed, which would require the discontinuation of the drug. The dose of $\mathrm{BAB}$ was selected individually to a heart rate of $55-60 / \mathrm{min}$. calculated on a 10 -second ECG recording at rest or the maximum tolerance. Monitoring of ECG data did not reveal a negative effect of BAB on atrioventricular conduction and QT interval.

Analysis of CAG records showed complete comparability of groups I and II in the number of affected vessels and, accordingly, endovascular revascularization - the number of stents installed (see Table III).

Patients in all study groups had no differences in baseline therapy, primarily in drugs and statin doses (see Table IV).

In all study groups, the vast majority of patients received angiotensin-converting enzyme inhibitors. 
As shown in Table V, in patients with MI there are significant shifts in endothelial function. Thus, the level of NOS-2 was in groups I - III $4851.1 \pm 166.5,4837.7$ $\pm 159.3,4853.4 \pm 165.4 \mathrm{pg} / \mathrm{mL}$, respectively, without a significant difference (all $\mathrm{p}>0.05$ ) against $4095.1 \pm 161.9$ $\mathrm{pg} / \mathrm{mL}$ in CG ( $\mathrm{p}<0.05$ compared to groups I, II and III). Similar changes are observed in the study of ET-1 levels (initial levels in groups I - III $62.1 \pm 5.4,63.1 \pm 3.9$, $62.3 \pm 4.8 \mathrm{pg} / \mathrm{mL}$, respectively, without significant difference (all $\mathrm{p}>0.05$ ) against $50.6 \pm 5.7 \mathrm{pg} / \mathrm{mL}$ in $\mathrm{CG}(\mathrm{p}<0.05$ compared to groups I, II and III). The data correspond to the results of V. Wilmesetal (2020) [5] obtained in an experiment on small cohort

During the 6-month follow-up, positive dynamics of NOS-2 and ET-1 was observed. The level of NOS-2 in groups I - III was $4272.3 \pm 162.7,4629.7 \pm 161.2$, $4634.2 \pm 163.5 \mathrm{pg} / \mathrm{mL}$, respectively (all $\mathrm{p}<0.05$ compared to baseline). Such dynamics can be explained by constant intake of statins and ACE inhibitors in these groups, which have pleiotropic effects and reduce endothelial dysfunction. However, in group I the decrease in NOS2 was significantly $(\mathrm{p}<0.05$ compared with indicators of groups II and III) more pronounced, which can be explained by the additional positive effect of nebivalol, a drug with NO activity. Analysis of the dynamics of ET-1 showed that within 6 months there was a significant decrease (all $\mathrm{p}<0.05$ compared to baseline) of its level in all groups (group I - 54.7 \pm 6.1 , II $-59.6 \pm 3$,3 and in group III $-60.2 \pm 4.2 \mathrm{pg} / \mathrm{mL}$ ). The use of Nebivolol is associated with an increase in the effectiveness of basic treatment - there is a significant decrease $(p<0.05)$ compared with indicators of groups II and III. However, no normalization of NOS-2 and ET- 1 to the CG level was observed in any group, which may be due to the relatively short follow-up period in combination with significant initial changes.

Significant changes are observed when assessing the level of NOS-3 (see Table V). Thus, the level was in I group $-3088.1 \pm 153.1$, in II $-3093.4 \pm 157.4$ and in III group $-3086.3 \pm 152.3 \mathrm{pg} / \mathrm{mL}$ without a significant difference (all $\mathrm{p}>0.05$ ) against $3545.0 \pm 159.8 \mathrm{pg} / \mathrm{mL}$ in CG ( $p<0.05$ compared with groups I, II and III). The level increased in patients of I group to $3428.9 \pm 154.3$, in II group $-3212.4 \pm 149.7$ and III group $-3248.7 \pm 155.1$ $\mathrm{pg} / \mathrm{mL}$ (all $\mathrm{p}<0.05$ compared to baseline). Similarly to other indicators, Nebivalol in patients is associated with a more pronounced increase in NOS-3 levels ( $p<0.05$ compared with groups II and III).

\section{DISCUSSION}

The level of NOS-3 is determined by genotype, the gene expression depends on many factors [6]. This may explain its changes during the treatment of MI, which indicates new opportunities in the treatment of such patients. This accounts the widespread use of new drugs, such as Nebivalol, which have an effect on NO synthase. It is possible that the proven effectiveness of such $B A B$ in the group of elderly patients will be useful in a group of young men. Moreover, there are indications of a positive effect on erectile function of Nebivalol, compared with other BAB [7]. This expands the need for further study of NO exchange and the opportunities to influence it in this group of patients.

Conclusions. Significant changes in markers of endothelial dysfunction, namely NOS3/eNOS, NOS2/iNOS and ET-1, are observed in young male patients of the Ukrainian population with MI. During 6 months of treatment, positive changes were observed in the form of an increase in NOS-3 levels and a significant decrease in ET-1 and NOS-2 levels. The inclusion of Nebivolol in the basic therapy for this group of patients is associated with an additional positive effect on the normalization of levels NO synthase and the reduction of ET-1.

\section{REFERENCES}

1. Eitel I., Nowak M., Stehl C. et al. Endothelin-1 release in acute myocardial infarction as a predictor of long-term prognosis and noreflow assessed by contrast-enhanced magnetic resonance imaging. Am Heart J. 2010;159(5):882-90. doi: 10.1016/j.ahj.2010.02.019.

2. Sorrentino S.A., Doerries C., Manes C. et al. Nebivolol exerts beneficial effects on endothelial function, early endothelial progenitor cells, myocardial neovascularization, and left ventricular dysfunction early after myocardial infarction beyond conventional $\beta 1$-blockade. J Am Coll Cardiol. 2011;57(5):601-11. doi: 10.1016/j.jacc.2010.09.037.

3. Aragon J.P., Condit M.E., Bhushan S. et al. Beta3-adrenoreceptor stimulation ameliorates myocardial ischemia-reperfusion injury via endothelial nitric oxide synthase and neuronal nitric oxide synthase activation. J Am Coll Cardiol. 2011;58(25):2683-91. doi: 10.1016/j. jacc.2011.09.033.

4. van Veldhuisen D.J., Cohen-Solal A., Bohm M. et al. Beta-blockade with nebivolol in elderly heart failure patients with impaired and preserved left ventricular ejection fraction: Data From SENIORS (Study of Effects of Nebivolol Intervention on Outcomes and Rehospitalization in Seniors With Heart Failure). J Am Coll Cardiol. 2009 ;53(23):2150-8. doi: 10.1016/j.jacc.2009.02.046.

5. Wilmes V., Scheiper S., RoehrW. et al. Increased inducible nitric oxide synthase (iNOS) expression in human myocardial infarction. Int J Legal Med. 2020;134(2):575-81. doi: 10.1007/s00414-019-02051-y.

6. Nasyrova R. F., Moskaleva P. V., Vaiman E. E. et al. Genetic Factors of Nitric Oxide's System in Psychoneurologic Disorders. Int. J. Mol. Sci. 2020;21:1604. doi:10.3390/ijms21051604.

7. Sharp R., Gales B. Nebivolol versus other beta blockers in patients with hypertension and erectile dysfunction. Ther Adv Urol. 2017; 9(2): 59-63. doi:10.1177/ 1756287216685027.

Improvement of prevention, treatment and rehabilitation of patients with arterial hypertension and coronary heart disease with comorbid pathology in outpatient and inpatient settings. № 0119U001045. Government funding.

\section{ORCID and contributionship:}

Ievgenii V.Andrieiev: 0000-0002-0727-8166 ${ }^{A, C}$

Yulia M.Makukha: 0000-0003-4219-3245 B,D

Anatoliy M.Kravchenko: 0000-0001-6863-0197 ${ }^{F}$

Ludmila V. Gayova: 0000-0001-6186-3000 ${ }^{E}$ 


\section{Conflict of interest:}

The Authors declare no conflict of interest.

\section{CORRESPONDING AUTHOR}

\section{levgenii V. Andrieiev}

Bogomolets National Medical University

13, T. Shevchenko blvd. 01601 Kyiv, Ukraine

tel:+380679098291

e-mail: therapevt@gmail.com

Received: 13.11 .2020

Accepted: 06.03.2021

A - Work concept and design, B - Data collection and analysis, C - Responsibility for statistical analysis,

$\mathbf{D}-$ Writing the article, $\mathbf{E}-$ Critical review, $\mathbf{F}$ - Final approval of the article 